Supplement of Nat. Hazards Earth Syst. Sci. Discuss., 3, 6615-6649, 2015

http://www.nat-hazards-earth-syst-sci-discuss.net/3/6615/2015/

doi:10.5194/nhessd-3-6615-2015-supplement

(C) Author(s) 2015. CC Attribution 3.0 License.

(c) (i)

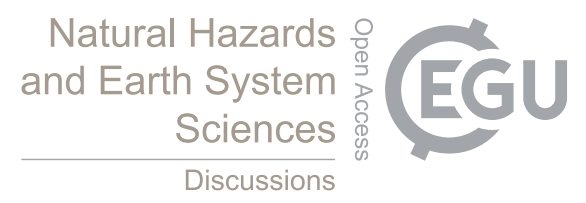

Supplement of

\title{
A spatial Bayesian network model to assess the benefits of early warning for urban flood risk to people
}

\section{S. Balbi et al.}

Correspondence to: S. Balbi (stefano.balbi@bc3research.org)

The copyright of individual parts of the supplement might differ from the CC-BY 3.0 licence. 
Questionnaire for the calibration of a Bayesian Network devoted to the estimation of flood damage costs to people. Application to the city of Zurich (alluvial cone of the Sihl river basin)

Estimated Time: $20 \mathrm{~min}$.

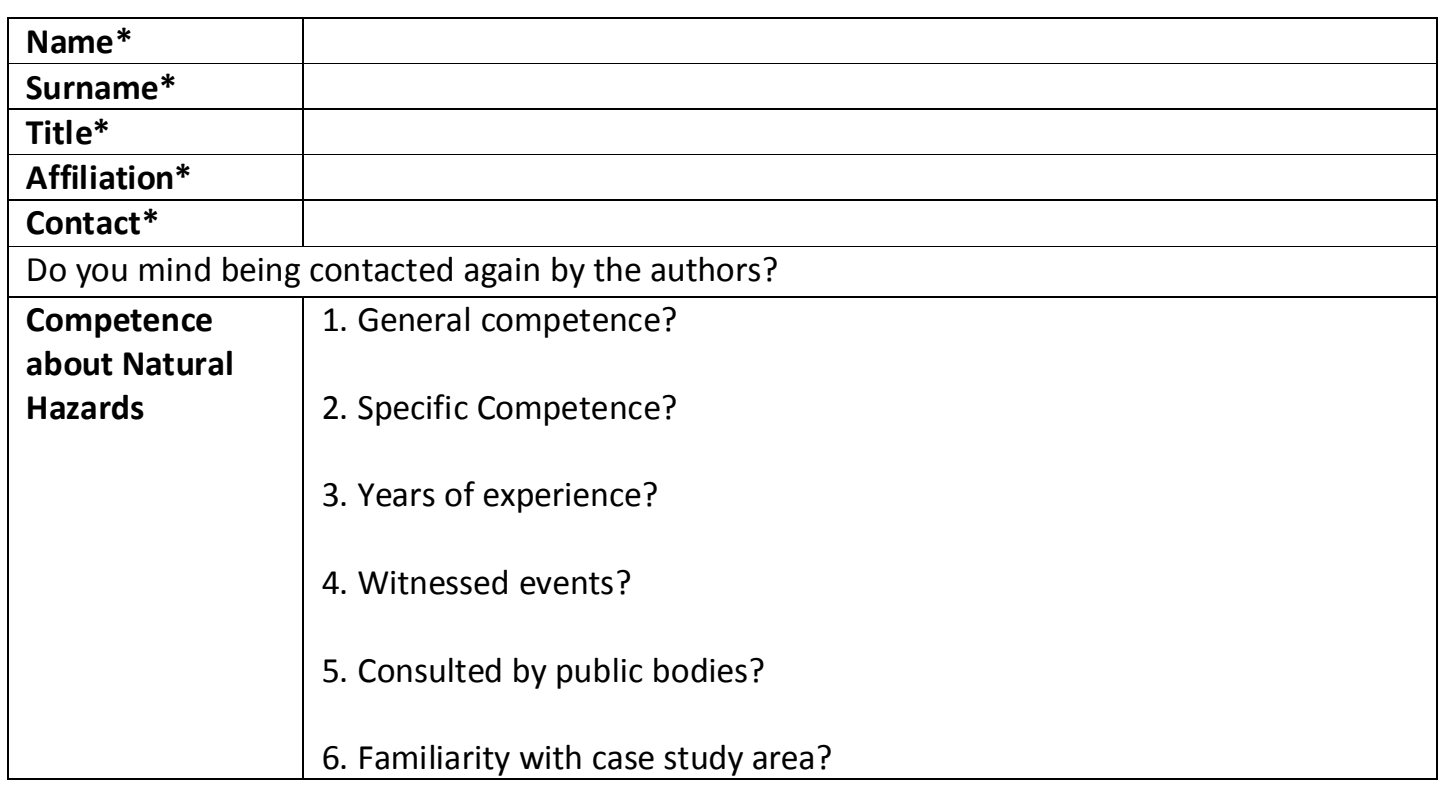

* These fields are optional, but of relevance for the research.

\section{Rationale}

This projects aims at modelling flood damage to people through the use of Bayesian Networks (BN). In this study a BN is used for the probabilistic assessment of the influence of different factors on the risk to society. Further information about the methodology is available here: http://papers.ssrn.com/sol3 /papers.cfm?abstract id=2175124. Thiswork will build a spatially distributed BN model. This questionnaire will be used to calibrate the $\mathrm{BN}$, so that it can reflect the expert opinions you and others provide.

\section{Case study: Zurich, Sihl river}

The study area $\left(77.97 \mathrm{~km}^{2}\right)$ covers the lower part of the Sihl valley and includes the city of Zurich, with its 21 districts, and 5 other municipalities. About 10,000 properties are located in hazard zones.
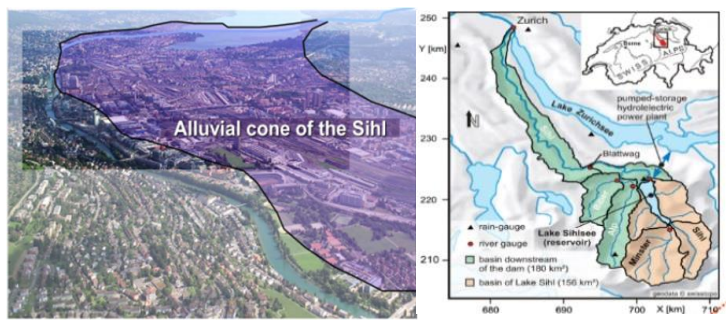

\section{Explanation of model and variables for a given spatial point}

We define Risk as a function of: Hazard (H) (flood event occurrence); Vulnerability (V) (intrinsic to the affected system) and Exposure (E) (presence of targets). 


\subsection{Hazard}

Our model describes $\mathbf{H}$ in terms of velocity, the speed of floodwater [between 0.25 and 4.25 $\mathrm{m} / \mathrm{s}$ ], depth of flood [between 0 and $4 \mathrm{~m}$ ], and debris factor, i.e. presence of floating dangerous debris in floodwater. We define 3 scenarios of $\mathbf{H}$ (HO/low, $\mathbf{H 1} /$ moderate, $\mathbf{H 2} /$ high), exemplified narratively in the questions.

\subsection{Vulnerability}

We describe $\mathbf{V}$ in terms of coping ability, risk governance, early warning systems (EWS) effectiveness and physical susceptibility.

- We represent coping ability as a function of the percentage of old and disabled people, and the percentage of non-native speakers (e.g. newcomers, foreigners).

- Risk governance is articulated into risk awareness and emergency governance, i.e. how conscious are the affected people of living in a risky area, and how effective are the means and the preparation of emergency personnel (i.e. civil protection, police, volunteers, etc.).

- Early warning effectiveness is articulated into EWS reliability, i.e. how reliable is the EWS in predicting the flooding event, and EWS lead time, i.e. how much time in advance the warning is given [between 1 hour and 3 days ].

- Susceptibility is articulated into speed of onset, i.e. the speed at which the discharge wave is rising, and housing type, describing the number of stories in the buildings where people live, including the presence of basements

We define 3 scenarios of $\mathbf{V}$ (V0/low, $\mathbf{V} \mathbf{1} /$ medium, $\mathbf{V} \mathbf{2} / \mathbf{h i g h}$ ), also exemplified narratively in the questions.

\subsection{Exposure}

Our model describes $\mathbf{E}$ as the presence of people. $\mathbf{E}$ is based on the density of the resident and transient population in the study area.

\section{Data elicitation}

We have identified combinations of our scenarios of $\mathbf{H}$ and $\mathbf{V}$, and we ask you to rank, using $a$ number from 0 to 100, the likely effect on an average individual for each scenario. The responses we requests concern:

1. Likelihood of material damages;

2. Likelihood of non-fatal physical injury;

3. Likelihood of posttraumatic stress disorder (PTSD);

4. Likelihood of death.

You will find question groups for each scenario of $\mathbf{H}$, with increasing levels of $\mathbf{V}$. Your answers will be checked for consistency; for example, increasing scores will be expected for increasing levels of $\mathbf{H}$ and $\mathbf{V}$, and responses that seem inconsistent will not be used for calibration.

The final question about $\mathbf{E}$ is meant to assess the effect of the increasing density of people over the area. This is necessary because the previous questions are about the average individual, so that the effects of density are not included.

If you prefer you can fill in only the last page (p. 6), making sure that the assumptions presented in the previous pages are clearly understood.

The data analysis will preserve source anonymity. For further questions contact: Stefano Balbi (stefano.balbi@bc3research.org)Basque Centre for Climate Change (BC3), Alameda Urquijo 4, 48008, Bilbao, Spain, +34 944014690 ext. 48. 


\section{Questions}

$5.1 \mathrm{Ho} /$ low hazard: flood depth is marginal (e.g. $<0.5 \mathrm{~m}$ ), water velocity is low (e.g. $<2 \mathrm{~m} / \mathrm{s}$ ) and there is no presence of debris.

QUESTION 5.1.1: If Vulnerability is low (VO) and Hazard is low (HO),

$V O=$ low E.g. People living in the area are mainly young families and university Vulnerability students, buildings are multistory, there have been recent floods before so people is aware and the emergency governance has been reinforced, an EWS is in place which directly reaches the people with constant updates.

What is the likelihood that an average individual experiences material damages, non-fatal injury, post-traumatic stress disorder (PTSD), and death?

Please fill in the 4 grey cells with a number between 0 and 100(low to high probability).

\begin{tabular}{|l|l|l|l|l|l|l|}
\hline Case & HAZARD & VULNERABILITY & $\begin{array}{l}\text { Material } \\
\text { damage }\end{array}$ & Injury & PTSD & Death \\
\hline $\mathbf{5 . 1 . 1}$ & HO & V0 & & & & \\
\hline
\end{tabular}

QUESTION 5.1.2: If Vulnerability is moderate (V1) and Hazard is low (H0),

$V 1=$ E.g. It's a residential area of individual houses with basement, where many moderate $\quad$ retired people reside. There have been flash floods before but the EWS is not Vulnerability at the technological level to deal with those. However, the civil protection agency is physically located within the area.

Please fill in the 4 grey cells with a number between 0 and 100 (low to high probability).

\begin{tabular}{|l|l|l|l|l|l|l|}
\hline Case & HAZARD & VULNERABILITY & $\begin{array}{l}\text { Material } \\
\text { damage }\end{array}$ & Injury & PTSD & Death \\
\hline $\mathbf{5 . 1 . 2}$ & H0 & V1 & & & & \\
\hline
\end{tabular}

QUESTION 5.1.3: If Vulnerability is high (V2) and Hazard is low (HO),

\begin{tabular}{|l|l|}
\hline $\begin{array}{l}V 2=h i g h \\
\text { Vulnerability }\end{array}$ & $\begin{array}{l}\text { E.g. Particularly sensitive targets like hospitals are present. It's the area where } \\
\text { most of the immigrants and foreigners reside. English basements are used. } \\
\text { The area is new to hydrological events so people is underprepared. A EWS is } \\
\text { not in place. The civil protection agency is not properly under control. }\end{array}$ \\
\hline
\end{tabular}

Please fill in the 4 grey cells with a number between 0 and 100 (low to high probability).

\begin{tabular}{|l|l|l|l|l|l|l|}
\hline Case & HAZARD & VULNERABILITY & $\begin{array}{l}\text { Material } \\
\text { damage }\end{array}$ & Injury & PTSD & Death \\
\hline $\mathbf{5 . 1 . 3}$ & $\mathrm{H} 0$ & $\mathrm{~V} 2$ & & & & \\
\hline
\end{tabular}

The data analysis will preserve source anonymity. For further questions contact: Stefano Balbi (stefano.balbi@bc3research.org)Basque Centre for Climate Change (BC3), Alameda Urquijo 4, 48008, Bilbao, Spain, +34 944014690 ext. 48. 
$5.2 \mathrm{H} 1 /$ moderate hazard: the depth is marginal (e.g. $<0.5 \mathrm{~m})$, but the water velocity is significant for an average person (e.g. $>2 \mathrm{~m} / \mathrm{s}$ ) and there is some debris factor.

QUESTION 5.2.1: If Vulnerability is low (V0) and Hazard is moderate (H1),

\begin{tabular}{|l|l|}
\hline$V O=$ low & $\begin{array}{l}\text { E.g. People living in the area are mainly young families and university } \\
\text { Vulnerability } \\
\text { students, buildings are multistory, there have been recent floods before so } \\
\text { people is aware and the emergency governance has been reinforced, an EWS } \\
\text { is in place which directly reaches the people with constant updates. }\end{array}$ \\
\hline
\end{tabular}

What is the likelihood that an average individual experiences material damages, non-fatal injury, post-traumatic stress disorder (PTSD), and death?

Please fill in the 4 grey cells with a number between 0 and 100 (low to high probability).

\begin{tabular}{|l|l|l|l|l|l|l|}
\hline Case & HAZARD & VULNERABILITY & $\begin{array}{l}\text { Material } \\
\text { damage }\end{array}$ & Injury & PTSD & Death \\
\hline $\mathbf{5 . 2 . 1}$ & H1 & V0 & & & & \\
\hline
\end{tabular}

QUESTION 5.2.2: If Vulnerability is moderate (V1) and Hazard is moderate (H1),

\begin{tabular}{|l|l|}
\hline $\begin{array}{l}\text { V1 } \\
\text { moderate } \\
\text { Vulnerability }\end{array}$ & $\begin{array}{l}\text { E.g. It's a residential area of individual houses with basement, where many } \\
\text { retired people reside. There have been flash floods before but the EWS is not } \\
\text { at the technological level to deal with those. However, the civil protection } \\
\text { agency is physically located within the area. }\end{array}$ \\
\hline
\end{tabular}

Please fill in the 4 grey cells with a number between 0 and 100 (low to high probability).

\begin{tabular}{|l|l|l|l|l|l|l|}
\hline Case & HAZARD & VULNERABILITY & $\begin{array}{l}\text { Material } \\
\text { damage }\end{array}$ & Injury & PTSD & Death \\
\hline $\mathbf{5 . 2 . 2}$ & H1 & V1 & & & & \\
\hline
\end{tabular}

QUESTION 5.2.3: If Vulnerability is high (V2) and Hazard is moderate (H1),

\begin{tabular}{|l|l|}
\hline$V 2=$ high & $\begin{array}{l}\text { E.g. Particularly sensitive targets like hospitals are present. It's the area where } \\
\text { molnerability of the immigrants and foreigners reside. English basements are used. } \\
\text { The area is new to hydrological events so people is underprepared. A EWS is } \\
\text { not in place. The civil protection agency is not properly under control. }\end{array}$ \\
\hline
\end{tabular}

Please fill in the 4 grey cells with a number between 0 and 100 (low to high probability).

\begin{tabular}{|l|l|l|l|l|l|l|}
\hline Case & HAZARD & VULNERABILITY & $\begin{array}{l}\text { Material } \\
\text { damage }\end{array}$ & Injury & PTSD & Death \\
\hline $\mathbf{5 . 2 . 3}$ & H1 & V2 & & & & \\
\hline
\end{tabular}

The data analysis will preserve source anonymity. For further questions contact: Stefano Balbi (stefano.balbi@bc3research.org)Basque Centre for Climate Change (BC3), Alameda Urquijo 4, 48008, Bilbao, Spain, +34 944014690 ext. 48. 
5.3. H2/high hazard: both the depth and the velocity are dangerous for an average person (e.g. $d>0.75 \mathrm{~m}$ and $v>2 \mathrm{~m} / \mathrm{s}$ ), and there is a relevant debris factor.

QUESTION 5.3.1: If Vulnerability is low (V0) and Hazard is high (H2),

\begin{tabular}{|l|l|}
\hline$V O=$ low & E.g. People living in the area are mainly young families and university \\
Vulnerability & $\begin{array}{l}\text { students, buildings are multistory, there have been recent floods before so } \\
\text { people is aware and the emergency governance has been reinforced, an EWS } \\
\text { is in place which directly reaches the people with constant updates. }\end{array}$ \\
\hline
\end{tabular}

What is the likelihood that an average individual experiences material damages, non-fatal injury, post-traumatic stress disorder (PTSD), and death?

Please fill in the 4 grey cells with a number between 0 and 100 (low to high probability).

\begin{tabular}{|l|l|l|l|l|l|l|}
\hline Case & HAZARD & VULNERABILITY & $\begin{array}{l}\text { Material } \\
\text { damage }\end{array}$ & Injury & PTSD & Death \\
\hline $\mathbf{5 . 3 . 1}$ & H2 & V0 & & & & \\
\hline
\end{tabular}

QUESTION 5.3.2: If Vulnerability is moderate (V1) and Hazard is high (H2),

\begin{tabular}{|l|l|}
\hline $\begin{array}{l}V 1 \\
\text { moderate } \\
\text { Vulnerability }\end{array}$ & $\begin{array}{l}\text { E.g. It's a residential area of individual houses with basement, where many } \\
\text { retired people reside. There have been flash floods before but the EWS is not } \\
\text { at the technological level to deal with those. However, the civil protection } \\
\text { agency is physically located within the area. }\end{array}$ \\
\hline
\end{tabular}

Please fill in the 4 grey cells with a number between 0 and 100 (low to high probability).

\begin{tabular}{|l|l|l|l|l|l|l|}
\hline Case & HAZARD & VULNERABILITY & $\begin{array}{l}\text { Material } \\
\text { damage }\end{array}$ & Injury & PTSD & Death \\
\hline $\mathbf{5 . 3 . 2}$ & H2 & V1 & & & & \\
\hline
\end{tabular}

QUESTION 5.3.3: If Vulnerability is high (V2) and Hazard is high (H2),

\begin{tabular}{|l|l|}
\hline $\begin{array}{l}\text { V2 }=\text { high } \\
\text { Vulnerability }\end{array}$ & $\begin{array}{l}\text { E.g. Particularly sensitive targets like hospitals are present. It's the area where } \\
\text { most of the immigrants and foreigners reside. English basements are used. } \\
\text { The area is new to hydrological events so people is underprepared. A EWS is } \\
\text { not in place. The civil protection agency is not properly under control. }\end{array}$ \\
\hline
\end{tabular}

Please fill in the 4 grey cells with a number between 0 and 100 (low to high probability).

\begin{tabular}{|l|l|l|l|l|l|l|}
\hline Case & HAZARD & VULNERABILITY & $\begin{array}{l}\text { Material } \\
\text { damage }\end{array}$ & Injury & PTSD & Death \\
\hline $\mathbf{5 . 3 . 3}$ & $\mathrm{H} 2$ & $\mathrm{~V} 2$ & & & & \\
\hline
\end{tabular}

The data analysis will preserve source anonymity. For further questions contact: Stefano Balbi (stefano.balbi@bc3research.org)Basque Centre for Climate Change (BC3), Alameda Urquijo 4, 48008, Bilbao, Spain, +34 944014690 ext. 48. 
5.4 $\mathrm{H}$ and $\mathrm{V}$ being equal ${ }^{1}$, how does an increased level of $\mathrm{E}$ (e.g. more densely populated areas or hotspots with more transient people) affect the risk to an average individual?

Increases proportionally (e.g. if $E \uparrow$ then $R \uparrow$ )

$\square$ Decreases proportionally (e.g. if $E \uparrow$ then $R \downarrow$ )

$\square$ Increases more than proportionally (e.g. if $E \uparrow$ then $R \uparrow \uparrow$ )

$\square$ Increases less than proportionally (e.g. if $E \uparrow \uparrow$ then $R \uparrow$ )

$\square$ Decreases more than proportionally (e.g. if $E \uparrow$ then $R \downarrow \downarrow$ )

$\square \quad$ Decreases less than proportionally (e.g. if $\mathrm{E} \uparrow \uparrow$ then $\mathrm{R} \downarrow$ )

$\square$ Does not change (e.g. if $E \uparrow$ then $R=$ )

5.5 Consistency Check. Following you can copy your previous answers and make sure that they are consistent. This is only for your own use and optional.

\begin{tabular}{|l|l|l|l|l|l|l|}
\hline Case & HAZARD & VULNERABILITY & $\begin{array}{l}\text { Material } \\
\text { damage }\end{array}$ & Injury & PTSD & Death \\
\hline $\mathbf{5 . 1 . 1}$ & H0 & V0 & & & & \\
\hline $\mathbf{5 . 1 . 2}$ & HO & V1 & & & & \\
\hline $\mathbf{5 . 1 . 3}$ & HO & V2 & & & & \\
\hline $\mathbf{5 . 2 . 1}$ & H1 & V0 & & & & \\
\hline $\mathbf{5 . 2 . 2}$ & H1 & V1 & & & & \\
\hline $\mathbf{5 . 2 . 3}$ & H1 & V2 & & & & \\
\hline $\mathbf{5 . 3 . 1}$ & H2 & V0 & & & & \\
\hline $\mathbf{5 . 3 . 2}$ & H2 & V1 & & & & \\
\hline $\mathbf{5 . 3 . 3}$ & H2 & V2 & & & & \\
\hline
\end{tabular}

Please add your comments and notes below. Suggestions are welcome.

Thank you for your knowledge and time.

\footnotetext{
${ }^{1}$ The model assumes the absence of a nonlinear dependence for reasons of tractability. The data analysis will preserve source anonymity. For further questions contact: Stefano Balbi (stefano.balbi@bc3research.org)Basque Centre for Climate Change (BC3), Alameda Urquijo 4, 48008, Bilbao, Spain, +34 944014690 ext. 48.
} 